\title{
Kikuchi hastalığı ve sistemik lupus eritematoz: Olgu sunumu
}

\author{
Kikuchi disease and systemic lupus erythematosus: a case report
}

\author{
Mustafa Özmen, Nuri Nazif Altıner*, Füsun Topçugil*, Murat Ermete**, Sakine Leyla Aslan* \\ İmir Atatürk Eğitim ve Araștırma Hastanesi, Romatoloji, *iç Hastalıkları, **Patoloji Kliniği, İzmir, Türkiye
}

\section{Özet}

Kikuchi hastalı̆ı $(\mathrm{KH})$ ateş, servikal lenfadenopati ve lökopeni ile karakterize iyi huylu ve kendini sınırlayan nadir bir hastalıktır. Benzer klinik ve histolojik özelliklere sahip oldukları için KH'nın, tedavi ve prognozu tamamen farklı olan sistemik lupus eritematoz (SLE), tüberküloz ve lenfoma ile ayıııı tanısı yapılmalıdır. Ayrıca nadir olarak KH ve SLE birlikte görülebilir. Bu olgu sunumunda KH ve SLE tanılarını eş zamanlı almış olan bir kadın hasta sunulmaktadır. (Türkderm 2014; 48: 47-50)

Anahtar Kelimeler: Kikuchi hastalı̆ı, sistemik lupus eritematoz, lenfadenopati, romatizmal hastalıklar

\section{Summary}

Kikuchi disease (KD) is a rare, benign and self-limited condition characterized by fever, cervical lymphadenopathy and leukopenia. The differential diagnosis of KD should include systemic lupus erythematosus (SLE), tuberculosis and lymphoma because of similar clinical and histological features and entirely different treatment and prognosis. KD and SLE may present together. In this case report, we present a female patient who was diagnosed with KD and SLE simultaneously. (Turkderm 2014; 48: 47-50)

Key Words: Kikuchi disease, systemic lupus erythematosus, lympadenopathy, rheumatic disease

\section{Giriş}

Kikuchi hastalığı (KH) (Kikuchi-Fujimoto hastalığı veya histiyositik nekrotizan lenfadenit olarak da bilinir) ilk olarak 1972 yılında Japonya'da Kikuchi ve Fujimoto tarafından tanımlanmıştır. Genç kadınlar daha çok etkilenmektedir. Ateş, servikal lenfadenopati ve lökopeni karakteristik özellikleridir. Sebebi kesin bilinmeyen bu nadir hastalık genellikle kendini sınırlayan ve iyi huylu bir durumdur ${ }^{1-3}$. Kikuchi hastalığı sıklıkla tüberküloz, lenfoma ve sistemik lupus eritematoz (SLE) gibi bazı hastalıklar ile benzer klinik ve histolojik özelliklere sahiptir. Nadir olarak SLE KH'ye eşlik eder. KH tanısı SLE tanısından önce, eş zamanlı veya sonradan konulabilir ${ }^{4,5}$.
Bu yazıda eş zamanlı SLE ve KH tanıları alan bir kadın olgu sunulmaktadır.

\section{Olgu}

Yirmi yedi yaşında kadın hasta, 2 haftadır olan ateş, yüz ve gövdede döküntü ve boyunda ağrılı kitle şikayetleri ile iç hastalıkları polikliniğine başvurdu ve iç hastalıkları kliniğine yatırıldı. Yapılan fizik bakısında $39^{\circ} \mathrm{C}$ ateş, yüz ve gövdede makülopapüler döküntü tespit edildi (Resim 1 ve 2). Servikal, submandibular, aksiler ve inguinal bölgelerde 15-20 mm çapında ağrısız lenf nodları bulundu. Nörolojik sistem dahil diğer sistem fizik bakı bulguları olağan

Yazışma Adresi/Address for Correspondence: Dr. Mustafa Özmen, İzmir Atatürk Eğitim ve Araştırma Hastanesi, Romatoloji Polikliniği, İzmir, Türkiye GSM: +90 5334779308 E-posta: drmozmen@yahoo.com Geliş Tarihi/Received: 25.11.2013 Kabul Tarihi/Accepted: 25.12.2013 
sınırlardaydı. Laboratuvar çalışmasında artmış eritrosit sedimentasyon hızı (48 mm/s), lökopeni $\left(1860 / \mathrm{mm}^{3}\right)$, nötropeni $\left(1110 / \mathrm{mm}^{3}\right)$, anemi (hemoglobin 10,9 g/dl), artmış laktat dehidrogenaz (460 U/L- normali 140-280) ve ferritin (371 ng/ml- normali 14-150) düzeyleri bulundu İdrar sedimentinde 20-25 lökosit, 5-6 eritrosit ve 8-10 granüler silendir vardı ve 24 saatlik idrarda protein ekskresyonu 464 mg idi. Kan ve idrar kültürlerinde üreme olmadı. HIV, CMV ve Epstein-Barr virüs için yapılan serolojik testler negatifti. Periferik kan değerlendirmesinde lökopeni ve nötropeni görüldü. Kemik iliği biyopsisinde sadece hiperselülerite dışında özellik yoktu. Ekokardiyografik incelemede

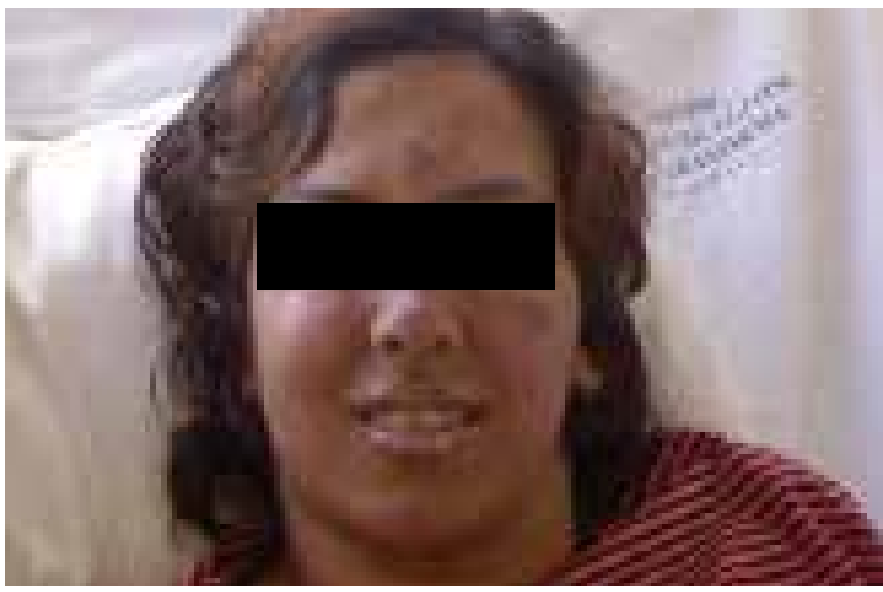

Resim 1. Hastanın yüzündeki eritematöz döküntüler

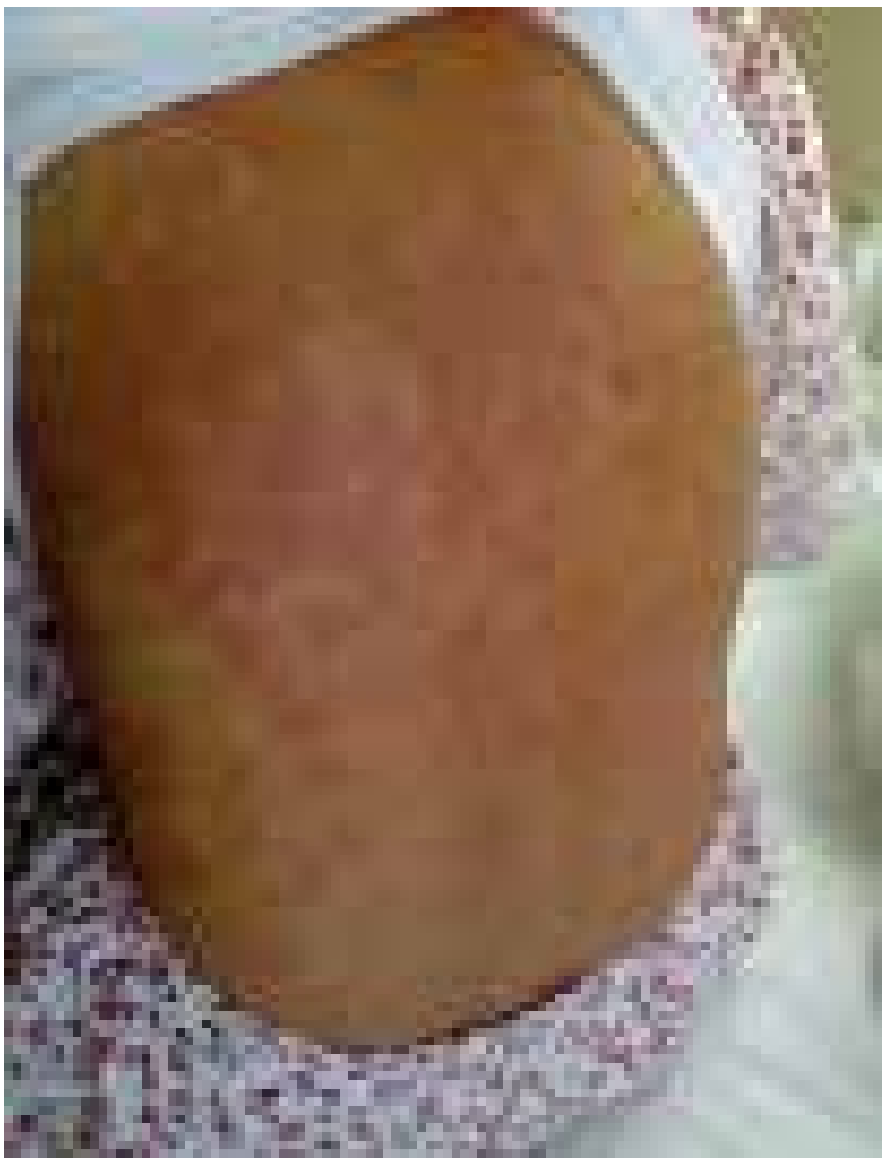

Resim 2. Hastanın gövdesindeki eritematöz döküntüler patolojik bulgu yoktu. Antinükleer antikor (ANA) 1/1000 titrede, homojen ve granüler paternde pozitifti. Anti-dsDNA antikoru negatif fakat anti-Sm antikoru pozitifti. C3 (69 mg/dL-normali 90-180) ve C4 (0 mg/dL- normali 10-40) düzeyleri çok düşüktü. Deri lezyonundan yapılan biyopsi SLE ile uyumluydu. Servikal lenf nodundan yapılan ince iğne aspirasyon biyopsisinde nekrotizan lenfadenit izlendi (Resim 3). Tanısal işlemler devam ederken hastanın jeneralize tonik klonik nöbeti oldu. Kranial magnetik rezonans görüntülemede patolojik bulgu yoktu. EEG'de ise epileptiform anormalikler izlendi.

Ateş, lenfadenopati, nötropeni ve nekrotizan lenfadeniti gösteren biyopsi ile KH tanısı konuldu. ANA ve anti-Sm antikor pozitfliği, idrar bulguları, düşük kompleman düzeyleri, başka sebep olmadan nöbet ve deri biyopsisi bulguları ile aynı zamanda SLE tanısı konuldu. Böbrek biyopsisi planlanmıştı fakat hasta kabul etmediği için yapılamadı.

Tedavi olarak nörolojik ve böbrek tutulumu olması nedeniyle aylık pulse siklofosfamid ve yüksek doz metilprednisolon başlandı. Tedavinin üçüncü gününde ateş düştü ve beşinci gününde lenf nodlarının büyüklüğü geriledi. Hasta tedavisine (aylık pulse siklofosfamid, tedricen azaltılan metilprednizolon, düşük doz asetil salisik asit) ayaktan devam etmek üzere taburcu edildi.

\section{Tartışma}

Kikuchi hastalığı ateş, lenfadenopati ve lökopeni ile karakterize,2-3 dekattaki (7-75 yaş, ortalama yaş 28 yıl) bireyleri etkileyen bir hastalıktır. Kadın:erkek oranı yaklaşık 4:1'dir6. Hastaların çoğu uzak doğudan bildirilmiştir fakat dünyadaki kesin bölgesel dağılımı bilinmemektedir ${ }^{4,7}$.

Kikuchi hastalığının etyolojisi bilinmemektedir. İnfeksiyöz ajanlara karşı T hücre ve histiyosit immün yanıtı olduğu düşünülmektedir ${ }^{6}$. Epstein-Barr virüs, sitomegalovirüs, varisella zoster virüs, insan herpes virüs tip 6, HIV, yersinia enterokolitika ve toksoplazma gibi pek çok mikroorganizma suçlanmıştır ${ }^{8-13}$. Fakat bugüne kadar bu konuda kesin kanıt bulunamamıştır. Genetik yatkınlık da önemli bir rol oynayabilir ${ }^{14}$. Kubota ve ark.'ı hastalığın akut fazında yükselen ve iyileşme döneminde normale dönen serum interferon-gamma ve interlökin-6 düzeyleri, Kato ve ark.'। ise "soluble" Fas ligand düzeyleri bildirmişlerdir ${ }^{15,16}$.

En sık klinik yansıma ağrısız veya hafif hassas olabilen ve sıklıkla ateşin eşlik ettiği tek taraflı posterior servikal lenfadeopatidir. Lenf nodu

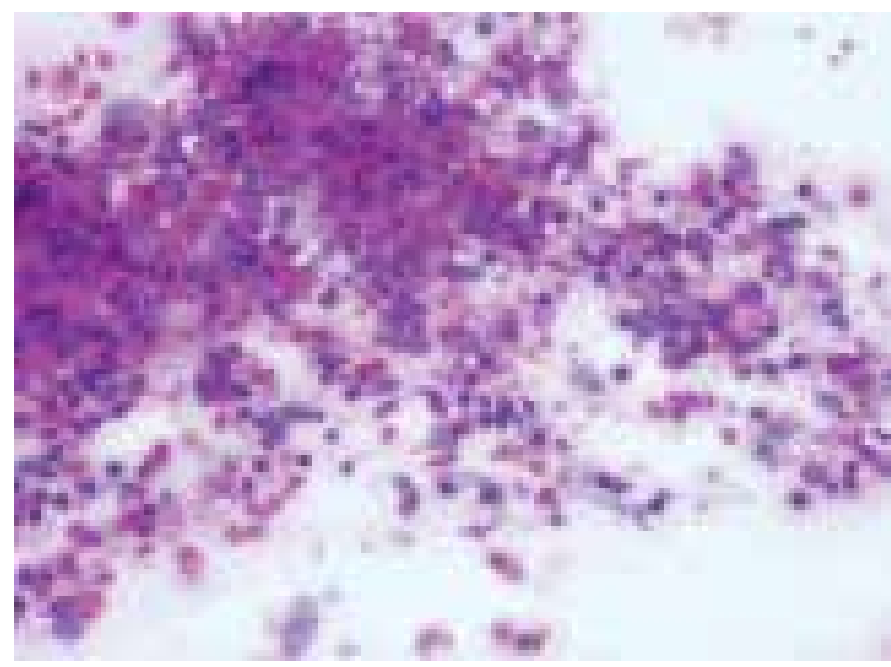

Resim 3. Nekrotik zeminde nükleer artıklar, immünoblastlar ve lenfositler (HEX 480) 
tutulumu daha yaygın olabilir ve aksiller, mediastinal ve inguinal gibi diğer bölgelerdeki lenf nodları tutulabilir. Nadir olarak splenomegali, parotis büyümesi, deri döküntüsü, artralji, myalji, aseptik menenjit, kemik iliğinde hemofagositoz ve interstisyel akciğer hastalığı görülür. Lenf nodları genellikle orta düzeyde büyümüştür (1-2 cm çapında) fakat bazen daha büyük olabilir $(\leq 7 \mathrm{~cm})$. Tipik olarak sert, düzgün yüzeyli, ayrı ayrı ve mobildir. Lenf nodu büyümesine sıklıkla künt veya akut ağrı eşlik eder.

Deri tutulumu KH olgularının \%30'unda görülebilir. Deri lezyonları makülopapüler, kızamıkçık veya ilaç döküntüsü benzeri döküntü, ürtiker veya yaygın eritem şeklinde olabilir. Fakat patognomonik değildirler ${ }^{17}$.

Laboratuvar sonuçları nonspesifiktir ve yükselmiş eritrosit sedimentasyon hızı, hafif lenfositoz ve nötropenin eşlik ettiği lökopeni, hafif karaciğer fonksiyon testleri anormallikleri ve yüksek serum laktik asit dehidrogenaz düzeylerini içerir ${ }^{4,7,10,18,19}$.

Lenf nodlarının histolojik değerlendirilmesi kesin tanı için gereklidir. KH'nin kendini sınırlayan doğasına rağmen lenfoma gibi daha ciddi hastalıkları dışlamak için biyopsi yapılmalıdır. Eksizyonel biyopsi daha çok önerilir, fakat son zamanlarda ince iğne aspirasyon biyopsisinin yeterli tanısal değerinin olduğu bildirilmiştir ${ }^{20,21}$. Bizim hastamızda ince iğne aspirasyon biyopsisi yapılarak tanı konuldu.

Lenf nodu biyopsisinde morfolojik olarak karyoreksis ve nötrofilin az olduğu nekrotizan lenfadenit görülür. Karakteristik histopatolojik bulgular; lenfoid doku yıkımı, yamalı fibrinoid nekroz odakları, nekrotik dokunun etrafında köpüksü sitoplazması olan taşlı yüzük ve kresent şekilli histiyositler, çeşitli hücrelerin (histiyosit, plazma hücresi, immunoblast, küçük ve/veya dev lenfositler) karyoreksis ve apoptozis artıklarıdır. Illginç olarak nekroza karşı nötrofilik veya eozinofilik reaksiyon yoktur. Bazı otörlere göre histiyositik proliferasyon (granülomatöz inflamasyon olmadan plazmasitoid monosit, küçük lenfositler, aktive $\mathrm{T}$ lenfositler ve plazma hücrelerinden oluşur) tek başına nekroza göre daha karakteristiktir ${ }^{22-24}$. Deri lezyonlarının histopatolojik incelemesi genellikle lökositoklastik vasküliti gösterir ${ }^{25}$. Sistemik lupus eritematoz, tüberküloz ve lenfomada da nekrotizan lenfadenit görülebildiği için bu hastalıklar ayırıcı tanıda akılda tutulmalıdır². Ayrıca mikst bağ dokusu hastalığı, Still hastalığı gibi diğer bazı otoimmün romatolojik hastalıklar da $\mathrm{KH}$ ile ilişkili olabilir²7. Kikuchi hastalığı ile SLE arasında ilişki henüz tam olarak anlaşılamamıştır. Prognoz ve tedavileri tamamen farklı olduğu için bu iki hastalığı ayırt etmek önemlidir. Fakat pek çok ortak klinik ve histolojik özellikleri (başlangıç yaşı, kadın egemenliği, jeneralize lenfadenopati, eritematöz deri lezyonları, ateş, artralji, kilo kaybı ve nekrotizan lenfadenit) olduğu için bu her zaman kolay olmamaktadır. Hatta KH'nın virüsün tetiklediği lenfositlerin neden olduğu SLE benzeri otoimmün bir durum olduğu ileri sürülmüştür ${ }^{28}$. SLE'ye özel antikorlar, hematoksilen cisimcikler ve lupus lenfadenitindeki vaskülit ayırıcı tanı yapmaya yardımcı olur 7,29,30.

Küçükardalı ve ark.'nın yazdığı bir derlemede 244 Kikuchi hastası değerlendirilmiştir4. Otuz iki hasta (\%13) SLE ile ilişkili bulunmuştur: 18 (\%56) hastada tanılar eş zamanlı, 6 (\%19) hastada SLE tanısı daha sonra ve 4 (\%12) hastada ise SLE tanısı daha önce konulmuştur. Dört (\%12) hasta SLE kriterlerini karşılamamış ve inkomplet SLE olarak kabul edilmiştir. Başka bir derlemede Santana ve ark. SLE ve $\mathrm{KH}$ birlikteliği olan 35 hasta bildirmişlerdir ${ }^{5}$. Ortalama yaş 29,1 $\pm 8,98$ yıl (10-46) ve kadın:erkek oranı 3,37:1'miş. SLE tanısı 7 hastada (\%20) KH tanısından önce, 14 hastada (\%40) eş zamanlı ve 14 hastada (\%40) ise daha sonra konulmuştur. KH tanısının SLE tanısı ile eş zamanlı veya daha sonra konulduğu hastalarda tedavi olarak kortikosteroid ve hidroksiklorokin kullanma eğiliminin belirgin olduğu bildirilmiştir. Diğer taraftan $\mathrm{KH}$ tanısı daha önce konulduğunda izole bir durum olarak düşünülmüş ve genellikle iyi huylu ve kendini sınırlayan doğası ve haftalar veya aylar içinde kendiliğinden iyileşmesi nedeniyle tedavisiz izlenmiştir.

Sistemik lupus eritematozlu bir hastada lenf nodu büyümesi lupus lenfadeniti, KH, tüberküloz gibi infeksiyöz lenfadenit veya lenfomaya bağlı olabilir. SLE'li bir hastada lenfadenopati tespit edildiğinde ince iğne aspirasyon biyopsisi yeterli tanısal değere sahip olabilir, fakat kesin karar verilemeyen kuşkulu durumlarda eksizyonel biyopsi yapılmalı ve tecrübeli bir patolog tarafından değerlendirilmelidir ${ }^{21,31,32}$. Kikuchi hastalığının etkili bir tedavisi yoktur. Fakat çoğu hasta 1 ile 6 ay içerisinde kendiliğinden iyileşir. Hastalığın tekrarlaması nadirdir ${ }^{33}$. KH bazen ölümcül olabilir; kardiyak yetmezlik, pulmoner hemoraji, koagülopati ve multiorgan yetmezliğine bağlı ölümler bildirilmiştir ${ }^{34-36}$. Ciddi ve kalıcı semptomu olan hastalar kortikosteroid tedavisinden belirgin fayda görmüştür ${ }^{37}$. Tekrarlayan $\mathrm{KH}$ olan bir olgu hidroksiklorokin ile başarılı olarak tedavi edilmiştir ${ }^{38}$.

Sonuç olarak tedavi ve prognozu tamamen farklı olduğu için KH'nin, SLE, tüberküloz ve lenfoma gibi diğer hastalıklar ile ayırıcı tanısı yapılmalıdır. SLE'nin KH'ye eşlik edebildiği akılda tutulmalıdır.

\section{Çıkar Çatışması Bildirimi}

Yazarlar her hangi çıkar çatışması olmadığını bildirmektedir.

\section{Kaynaklar}

1. Fujimoto $\mathrm{Y}$, Kojima $\mathrm{Y}$, Yamaguchi $\mathrm{K}$ : Cervical subacute necrotising lymphadenitis. Naika 1972;20:920-7.

2. Kikuchi M: Lymphadenitis showing focal reticulum cell hyperplasia with nuclear debris and phagocytes. Acta Hematol Jpn 1972;35:379-80.

3. Tsang WY, Chan JK, Ng CS: Kikuchi's lymphadenitis: a morphologic analysis of 75 cases with special reference to unusual features. Am J Surg Pathol 1994;18:219-31.

4. Kucukardali $Y$, Solmazgül E, Kunter E, et al: Kikuchi-Fujimoto Disease: analysis of 244 cases. Clin Rheumatol 2007;26:50-4.

5. Santana A, Lessa B, Galrao L, et al: Kikuchi-Fujimoto's disease associated with systemic lupus erythematosus: case report and review of the literature. Clin Rheumatol 2005; 24:60-3.

6. Meyer O. Kikuchi disease: Ann Med Interne 1999;150:199-204.

7. Dorfman RF, Berry GJ: Kikuchi's histiocytic necrotizing lymphadenitis: an analysis of 108 cases with emphasis on differential diagnosis. Semin Diagn Pathol 1988:5:329-45.

8. Dominquez DC, Torres ML, Antony S: Is human herpesvirus 6 linked to Kikuchi-Fujimoto disease? The importance of consistent molecular and serologic analysis. South Med J 2003;96:226-33.

9. George $\mathrm{TI}$, Jones $\mathrm{C}$, Zehnder JL, et al: Lack of human herpesvirus and Epstein-Barr virus in Kikuchi's histiocytic necrotizing lymphadenitis. Hum Pathol 2003;34:130-5.

10. Kapadia V, Robinson BA, Angus HB: Kikuchi's disease presenting as fever of unknown origin. Lancet 1989;2:1519-20.

11. Kikuchi M, Yoshizumi $T$, Nakamura $H$ : Necrotizing lymphadenitis: possible acute toxoplasmic infection. Virchows Arch A Pathol Anat Histol 1977;376:247-53.

12. Pileri SA, Sabattini.E, Costigliola $P$, et al: Kikuchi's lymphadenitis and HIV infectious. AIDS 1991;5:459-61.

13. Sumiyoshi Y, Kikuchi M, Minematu T, et al: Analysis of herpesvirus genomes in Kikuchi's disease. Virchows Arch 1994;424:437-40.

14. Tanaka T, Ohmori M, Yasunaga S, et al: DNA typing of HLA class II genes (HLA-DR-DQ and -DP) in Japanese patients with histiocytic necrotizing lymphadenitis (Kikuchi's isease). Tissue Antigens 1999;54:246-53.

15. Kubota M, Tsukamoto R, Kurokawa $K$, et al: Elevated serum interferon gamma and interleukin-6 in patients with necrotizing lymphadenitis (Kikuchi's disease). Br J Haematol 1996;95:613-5.

16. Kato K, Ohshima K, Anzai K, et al: Elevated serum-soluble Fas ligand in histiocytic necrotizing lymphadenitis. Int J Hematol 2001;73:84-6.

17. Seno A, Toriqoe R, Shimoe K, et al: Kikuchi's disease (histiocytic necrotizing, lymphadenitis) with cutaneuos involvement. J Am Acad Dermato 1994;30:504-6. 
18. Bailey EM, Klein NC, Cunha BA: Kikuchi's disease with liver dysfunction presenting as fever of unknown origin. Lancet 1989;2:986.

19. Yu HL, Lee SS, Tsai HC, et al: Clinical manifestations of Kikuchi's disease in Southern Taiwan. J Microbiol Immunol Infect 2005;38: 35-40.

20. Hsueh EJ, Ko WS, Hwang WS, et al: Fine-needle aspiration of histiocytic necrotizing lymphadenitis (Kikuchi's Disease). Diagn Cytopathol 1993;9:448-52.

21. Mannara GM, Boccato P, Rinaldo A, La Rosa F, Ferlito A: Histiocytic necrotizing lymphadenitis (Kikuchi-Fujimoto disease) diagnosed by fine needle aspiration biopsy. ORL J Otorhinolaryngol Relat Spec 1999;61:367371.

22. Ioachim HL, Ratech H: Kikuchi-Fujimoto lymphadenopathy. In: Ioachim $\mathrm{HL}$, Ratech $\mathrm{H}$ (eds) loachim's lymph node pathology, 3rd edn. Lippincott Williams, Philadelphia, USA; 2002. p219-221.

23. Kuo TT: Kikuchi's disease (histocytic necrotizing lymphadenitis): a clinicopathologic study of 79 cases with an analysis of histologic subtypes, immunohistology, and DNA ploidy. Am J Surg Pathol 1995;19:798-809.

24. Rivano MT, Falini $B$, Stein $H$, et al: Histiocytic necrotizing lymphadenitis without granulocytic infiltration (Kikuchi's lymphadenitis). Morphological and immunohistochemical study of eight cases. Histopathology 1987:11:1013-27.

25. Yasukawa K, Matsumura T, Sato-Matsumura KC, et al: Kikuchi's disease and the skin: case report and review of the literature. $\mathrm{Br} J$ Dermatol 2001;144:885-9.

26. Jayaraj SM, Lloyd J, Frosh AC, Patel KS: Kikuchi-Fujimoto's syndrome masquerading as tuberculosis. J Laryngol Otol 1999;113:82-4.

27. Gourley I, Bell AL, Biggart D: Kikuchi's disease as a presenting feature of mixed connective tissue disease. Clin Rheumatol 1995;14:104-7.
28. Imamura $M$, Ueno $H$, Matsuura A, Kamiya $H$, Suzuki T, Kikuchi $K$, Onoe T: An ultrastructural study of subacute necrotizing lymphadenitis. Am J Pathol 1982;107(3):292.

29. Martinez-Vazquez C, Hughes G, Bordon J, et al: Histiocytic necrotizing lymphadenitis, Kikuchi-Fujimoto's disease, associated with systemic lupus erythematosus. QJM 1997:90:531-3.

30. Menasce LP, Banerjee SS, Edmondson D, Harris M: Histiocytic necrotizing lymphadenitis (Kikuchi-Fujimoto disease): continuing diagnostic difficulties. Histopathology 1999;33:248-254.

31. Asano S, Akaike $Y$, Jinnouchi $H$, Muramatsu T, Wakasa H: Necrotizing lymphadenitis: a review of clinicopathological, immunohistochemical and ultrastructural studies. Hematol Oncol 1990;8:251-260.

32. Medeiros LJ, Kaynor B, Harris NL: Lupus lymphadenitis: report of a case with immunohistologic studies on frozen sections. Hum Pathol 1989;20:295299

33. Smith KG, Becker GJ, Busmanis I: Recurrent Kikuchi's disease. Lancet 1992;340:124.

34. Chmait RH, Meimin DL, Koo CH, Huffaker J: Hemophagocytic syndrome in pregnancy. Obstet Gynecol 2000; 95:1022-4.

35. Quintas-Cardama A, Fraga M, Cozzi SN, Caparrini A, Maceiras F, Forteza J: Fatal Kikuchi-Fujimoto disease:the lupus connection. Ann Hematol 2003;82:186-8

36. Wong CY, Law GT, Shum TT, Wong KY, Li YK: Pulmonary haemorrhage in a patient with Kikuchi disease. Monaldi Arch Chest Dis 2001;56:118-20.

37. Jang YJ, Park KH, Seok HJ: Management of Kikuchi's disease using glucocorticoid. J Laryngol 2000;114:709-11.

38. Rezai K, Kuchipudi S, Chundi V, Ariga R, Loew J, Sha BE: Kikuchi-Fujimoto disease: hydroxychloroquine as a treatment. Clin Infect Dis 2004;39:124-6. 